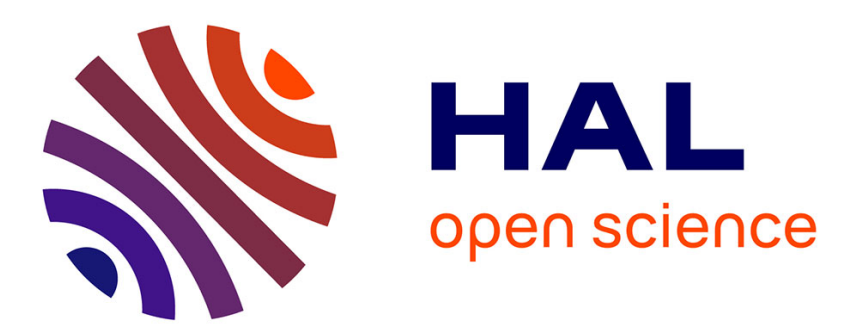

\title{
Characterisation of calcium phosphate layers grown on polycaprolactone for tissue engineering purposes
}

\author{
M. Lebourg, J. Suay Antón, J.L. Gomez Ribelles
}

\section{To cite this version:}

M. Lebourg, J. Suay Antón, J.L. Gomez Ribelles. Characterisation of calcium phosphate layers grown on polycaprolactone for tissue engineering purposes. Composites Science and Technology, 2010, 70 (13), pp.1796. 10.1016/j.compscitech.2010.07.017 . hal-00681638

\section{HAL Id: hal-00681638 \\ https://hal.science/hal-00681638}

Submitted on 22 Mar 2012

HAL is a multi-disciplinary open access archive for the deposit and dissemination of scientific research documents, whether they are published or not. The documents may come from teaching and research institutions in France or abroad, or from public or private research centers.
L'archive ouverte pluridisciplinaire HAL, est destinée au dépôt et à la diffusion de documents scientifiques de niveau recherche, publiés ou non, émanant des établissements d'enseignement et de recherche français ou étrangers, des laboratoires publics ou privés. 


\section{Accepted Manuscript}

Characterisation of calcium phosphate layers grown on polycaprolactone for tissue engineering purposes

M. Lebourg, J. Suay Antón, J.L. Gomez Ribelles

PII:

S0266-3538(10)00286-1

DOI:

10.1016/j.compscitech.2010.07.017

Reference:

CSTE 4771

To appear in:

Composites Science and Technology

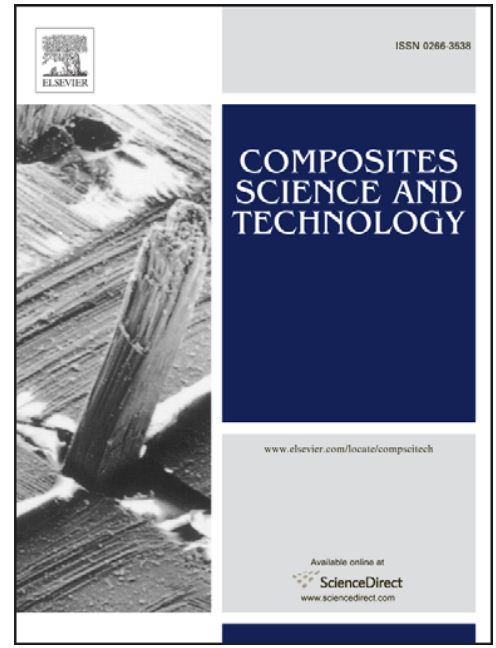

Received Date: $\quad 17$ December 2009

Revised Date: $\quad 15$ July 2010

Accepted Date: $\quad 19$ July 2010

Please cite this article as: Lebourg, M., Antón, J.S., Ribelles, J.L.G., Characterisation of calcium phosphate layers grown on polycaprolactone for tissue engineering purposes, Composites Science and Technology (2010), doi: 10.1016/j.compscitech.2010.07.017

This is a PDF file of an unedited manuscript that has been accepted for publication. As a service to our customers we are providing this early version of the manuscript. The manuscript will undergo copyediting, typesetting, and review of the resulting proof before it is published in its final form. Please note that during the production process errors may be discovered which could affect the content, and all legal disclaimers that apply to the journal pertain. 


\title{
Characterisation of calcium phosphate layers grown on polycaprolactone for tissue engineering purposes
}

\author{
$\underline{\text { M. Lebourg }}{ }^{1,2}$, J. Suay Antón ${ }^{1,2,3}$, J.L. Gomez Ribelles ${ }^{1,2,3}$ \\ 1. CIBER en Bioingeniería, Biomateriales y Nanomedicina, Campus Río Ebro - Edificio I+D \\ Bloque 5, $1^{a}$ planta C./ Poeta Mariano Esquillor s/n, 50018, Zaragoza, Spain \\ 2. Centro de Biomateriales e Ingeniería Tisular, Universidad Politécnica de Valencia, 46022, \\ Valencia, Spain. \\ 3. Regenerative Medicine Unit, Centro de Investigación Príncipe Felipe, Autopista del Saler 16, \\ 46013 Valencia, Spain
}

Corresponding author: M. Lebourg, Centro de Biomateriales e Ingeniería Tisular, Universidad Politécnica de Valencia, Edificio 8E- Bloque F-Nivel 1, Camino de Vera s/n, 46022 Valencia, Spain.

Mail: myle1@upvnet.upv.es. Tel: 0034963877007, ext. 88938. Fax: 0034963877276.

\section{Abstract}

Composites fabricated by biomimetic mineral precipitation on polymeric substrates are of interest for tissue engineering. As biological properties of such mineral layers vary with slight changes in composition, a good physical characterization is necessary in order to study their biological activity. In this work polycaprolactone sheets were subjected to air plasma treatment followed by nucleation of calcium phosphate seeds to activate the growth of an apatite-like coating when immersing in simulated body fluid. Two compositions of the SBF were prepared, one of them highly carbonated and the other with no carbonate or magnesium ions. Immersion of PCL in the high carbonate composition produced a low-crystallinity apatite-like layer while the absence of carbonate and magnesium ions yielded a high crystallinity apatite with low $\mathrm{Ca} / \mathrm{P}$ ratio that is likely partially hydrolyzed octacalciumphosphate (OCP). The morphology, crystal structure and composition of both types of coatings were characterised; osteoblast-like cell adhesion behaviour on different surfaces was observed by fluorescence and electron microscopy.

Keywords: Polymer(A); Ceramics(A); Surface Treatment(B); X-ray diffraction(D); Fourier Transform Infrared Spectroscopy(D); 


\section{Introduction}

Polymer-ceramic composites are of interest in the field of bone tissue engineering[1]: traditional polyesters used in biomedical field, as polylactide or polycaprolactone, are easily reabsorbed, show ductile properties, and can be easily processed to porous bodies as those used in tissue engineering, but they lack intrinsic bioactivity, thus not favouring any repair response from the body. On the other hand, ceramics from the calcium phosphate family, for example tricalcium phosphate and hydroxyapatites, have shown to induce a good response from bony cells. In fact they are currently in use in orthopaedics, though always with the drawback of fragility, scarce remodelling [2], and a difficulty in cutting to fill the defect shape. A combination of both material types thus reduces their drawbacks while benefiting from their respective advantages $[3,4,5]$. In recent years, much attention has been paid to the in vitro mineralisation of materials in protophysiological solutions (called simulated body fluid, hereafter mentioned as $\mathrm{SBF}$ ) as an important step for demonstrating corresponding in vivo bone bonding. The deposited calcium phosphate layer is described in literature mostly as "biomimetic apatite" for its composition is similar to that of bone mineral, that is to say a carbonated, calcium deficient and poorly crystalline apatite. Such nanostructured calcium phosphates, due to their high specific surface and soft preparation methods, are thought to be useful in tissue engineering as in vitro cell culture substrates for the study of cellmaterial interactions, or as carriers for proteins[6] or drugs (like biphosphonates or strontium containing drugs) while being easily degraded in the body if implanted. Based on the assumption that such a "bone-like mineral" would show good bioactive properties for the culture of cells, many studies have been carried out to prepare composites by precipitating mineral on different substrates to study the response of cells 
from bone lineage (osteoblasts, SAOS cells, mesenchymal cells, etc) to such mineral, with variable results $[7,8,9,10,11,12,13]$. Nevertheless, many papers do not characterise properly the mineral layer deposited, and as has been described among others by Chou et al.[14], the composition, $\mathrm{Ca} / \mathrm{P}$ ratio, present phases, crystallinity [15] and biosolubility of the mineral layer is of outermost importance with respect to the cell response, since cells show exquisite sensitivity to the smallest changes in roughness, chemistry, surface tension, crystal structure or culture medium composition[16]. In this paper, we describe how we obtained two differentiated calcium phosphate layers and their characterisation: we also present initial results of osteoblast-like cell culture on them.

Materials and Methods

\section{Sample preparation}

PCL (Polysciences, Mw=43000-50000 Da) and 1-4 dioxane (Scharlab 98\% pure) were used without further purification. PCL bulk samples were prepared by solvent casting from a PCL solution in dioxane ( $15 \%$ by weight) in Petri dishes. PCL with hydroxyapatite nanoparticles used in cell culture (Hap particles, $d<100 \mathrm{~nm}$, Sigma Aldrich) were prepared by solvent casting of PCL solution (15\% by weight in dioxane) with $20 \%$ of Hap (dispersed with ultrasound); these samples are referred thereafter as PCL-HAp-P samples. After solvent evaporation, films were rinsed in ethanol and vacuum dried to constant weight. Then $12 \mathrm{~mm}$-diameter disks were stamped out of the films and treated for apatite nucleation as described in [17]. Shortly after this, the samples were first treated with air plasma treatment, $300 \mathrm{~W}$ power, $90 \mathrm{~s}$ on each side in an Electronic Piccolo plasma chamber (Plasma Electronic GmbH, Germany). PCL and PCL HAp P samples were submitted to plasma treatment just before cell culture as effect of plasma on surface tension decreases with time. Then, samples were immersed 
for ten seconds in $\mathrm{CaCl}_{2}$ alcoholic solution $(0.1 \mathrm{mM}$, water/alcohol, w/a, 50/50), washed for 1 second in w/a 50/50 mixture, then immersed for $10 \mathrm{~s}$ in a $\mathrm{K}_{2} \mathrm{HPO}_{4}$ alcoholic solution $(0.1 \mathrm{mM}, \mathrm{w} / \mathrm{a}=50 / 50)$, and washed in water-alcohol mixture. This process was repeated 5 times. Subsequently, samples were freely suspended in modified SBFs, prepared following the methodology of Müller et al [18] out of concentrated solutions of $\mathrm{KCl}, \mathrm{NaCl}, \mathrm{NaHCO}_{3}, \mathrm{MgSO}_{4}-7 \mathrm{H}_{2} \mathrm{O}, \mathrm{CaCl}_{2}$, Tris- $\mathrm{HCl}$ buffer, $\mathrm{NaN}_{3}$, $\mathrm{KH}_{2} \mathrm{PO}_{4}$. The final electrolyte concentrations in SBFs are presented in Table 1. The main difference with Müller protocol was the concentration of sodium azide used as an antibacterial agent (when not prepared in totally aseptic conditions, SBF is likely to be colonised by phosphate eater bacteria [19]), this concentration was lowered from $1 \mathrm{~g} / \mathrm{l}$ to $10 \mathrm{mg} / \mathrm{l}$ as sodium azide is very toxic and $10 \mathrm{mg} / \mathrm{l}$ is sufficient for antibacterial activity: as a result, the sodium content in the prepared SBF was slightly lower than in traditional SBF, but it is hypothesized that since sodium is not a constituent of hydroxyapatite it does not modify its solubility product and thus does not influence its precipitation from the solution. Previous experiments (results not shown) showed that these SBFs are able to produce an apatite layer as do original SBF.

The SBF-A, (for amorphous), is a carbonate rich SBF prepared following the method by Müller and Müller and contains $15 \mathrm{mM} \mathrm{HCO}_{3}{ }^{2-}$ per litre. It was buffered at $\mathrm{pH}=7,4$ at $37^{\circ} \mathrm{C}$. It is expected to produce small-crystallite, low crystalline apatite deposit.

The SBF-C, for crystalline, is mainly a SBFx2 (with concentration of electrolytes doubled) containing neither magnesium nor carbonate, since these ions are known to act as crystal growth inhibitors, and buffered at $\mathrm{pH}=7$, (so as to lower the probability of spontaneous nucleation in the solution). It is expected to produce large-crystallite, highly crystalline apatite deposit. 
SBF was changed every 4 days and SBF immersion lasted 14 days. After SBF treatment, the samples were washed with distilled water and dried (except samples for cell culture). During washing, leaching of some mineral particles was observed.

\section{SEM observation}

Samples were cut and stuck to a metallic support using graphite adhesive tape, so that a piece of each face of the sample could be observed. Samples were gold sputtered and observed in a Hitachi S3000 electron microscope with acceleration tension of $20 \mathrm{kV}$ and work distance of $15 \mathrm{~cm}$. EDX analysis was performed and $\mathrm{Ca} / \mathrm{P}$ values were calculated from at least three large field analysis measurements.

\section{FTIR characterization}

The surface of the samples was scraped and the resulting powder was mixed with $\mathrm{KBr}$ in relation 1:1000 and compacted to a disk. FTIR analysis was performed in a FT-IR Bruker IFS60v analyzer provided with MCT detector in transmission mode from 550 to $4000 \mathrm{~cm}-1$ with a sensitivity of $4 \mathrm{~cm}^{-1}$. For evaluation of peaks, data was analyzed using the review on HAp characterization by Koutsopoulos [20].

\section{X-Ray Diffraction}

XRD analysis was carried out using a Siemens D-5000 diffractometer with $\theta / 2 \theta$ geometry equipped with parallel beam device for grazing incidence measurements and secondary monochromator. Measurements were performed in grazing incidence mode using monochromatic $\mathrm{Cu}_{(\mathrm{K} \alpha)}$ radiation, with incidence angle $1^{\circ}$ in order to observe mainly the mineral deposit, and scanning $2 \theta$ between 10 and 100 degrees with increment steps of 0,04 . For evaluation of peaks, data were compared with data from respective ICDD card files 026-1056(OCP) and 009-0432 (HAp).

\section{Cell culture}


Materials were sterilized with cold ethanol during two hours before cell culture. Before seeding, samples of pure PCL, PCL Hap-P, PCL-HAp-A and PCL-HAp-C (and glass coverslips as a control) were washed with PBS and coated with fibronectin solution in

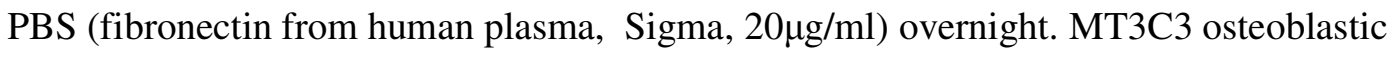
cells (Riken Cell Bank, Japan) at passage 20 were seeded at a density of $\sim 9 \times 10^{3}$ cells/cm2 in $400 \mu$ l standard growth medium (DMEM-LG supplemented with $1 \%$ Penicillin and Streptomycin, $1 \%$ glutamine), and allowed to adhere for $3 \mathrm{~h}$. At the end of the culture time, samples were washed twice with PBS, blocked with 3.7\%

paraformaldehyde (Sigma-Aldrich) during $60 \mathrm{~min}$ at $4^{\circ} \mathrm{C}$ and then stored in PBS at $4^{\circ} \mathrm{C}$ until biological characterization was performed.

\section{Biological characterization}

Fluorescence microscopy: The actin cytoskeleton was visualized using the green-fluorescent Bodipy FL Phalloidin (Invitrogen). After staining according to standard protocols, samples were glued on microscope slides with mounting medium containing DAPI (Vectashield, ATOM) for visualization of nuclei and stored in the dark at $4{ }^{\circ} \mathrm{C}$ until fluorescence microscopy was performed. Samples were observed in an inverted vertical microscope Axiovert200 (Zeiss) coupled to a CCD monochrome and color camera.

SEM: Samples were dehydrated in graded alcoholic solutions and air dried, then stuck to a metallic support using graphite adhesive tape. Samples were gold sputtered and observed in a JEOL JSM6300 electron microscope with acceleration tension of $15 \mathrm{kV}$ and work distance of $15 \mathrm{~cm}$.

Quantitative cell number analysis: In order to gain quantitative information on initial cell adhesion and seeding efficiency on the different surfaces, image analysis was performed using cell counting software[21]: for each sample type at least five pictures 
of DAPI stained nuclei at magnification 5x were recorded from two different samples and analyzed with CellC.

\section{$\underline{\text { Results }}$}

\section{Deposition of mineral layer}

Preliminary results showed that subjecting the samples to an air plasma treatment followed by nucleation treatment by immersion in $\mathrm{CaCl}_{2}$ and $\mathrm{K}_{2} \mathrm{HPO}_{4}$ solutions was effective in inducing the formation of an apatite-like layer. It is hypothesized that plasma treatment provokes the scission of ester bonds, thus multiplying the density of carboxylate moieties on the surface; those are known to be involved in the nucleation of calcium phosphates in simulated body fluid. Nevertheless, the effect of plasma alone is not decisive, and only slightly accelerates calcium phosphate nucleation on the surface of PCL. Alternative soaking in calcium and phosphate containing solutions after activation of the surface by plasma treatment or etching with sodium hydroxide has been shown to be effective in inducing apatite deposition. As described in [22] on the thermodynamical point of view, nucleation is the limiting step in apatite formation rate. Once nucleated, the apatite grows without induction from simulated body fluid.

\section{Morphology of mineral layer}

The morphology of the mineral layers deposited can be observed in Figure 1.

The surface of the apatite layer deposited by immersion in SBF-A medium, that we will call hereafter HAp-A, is formed by globular structure close to the typical cauliflower usually described for hydroxyapatite, and relatively smooth. At the contrary the surface of HAp-C (deposited in SBF-C) is formed by large plate-like crystals (width $\sim 2 \mu \mathrm{m}$ ) that resemble the morphology of gypsum flowers and show considerable roughness at small scale; this kind of plate-like crystals has been described for OCP[23] in the literature, and also in biomimetic apatite samples where it was inherited from crystallization of 
OCP as a primary phase that later on evolved towards hydroxyapatite, (observed by Müller et al. in OCP samples exposed to physiological conditions [24]). Layer thickness was determined on zones of the sample where the layer was peeled off from PCL surface and the profile appeared (Figure 2): it shown to be thicker for HAp-C $(\sim 12 \mu \mathrm{m})$ than for HAp-A $(\sim 6 \mu \mathrm{m})$ as expected from the respective ionic activities of the SBF solutions. As can be seen on profile for Hap-C, crystals grow vertically normal to the sample surface which should be related with preferred crystal orientation and was described by Müller in OCP samples [24]. Both sides of the samples had similar crystal microscopic morphology (see insets in Figure 1), whereas macroscopic morphology was a little different in roughness and surface profile which is likely to be due to different morphologies of the naked surfaces of PCL.

EDX analysis reveals that $\mathrm{Ca} / \mathrm{P}$ ratio of HAp-A is higher $(1,65)$ than that of HAp-C $(1,35)$, likely due to carbonate substitution for phosphate (B-type substituted apatite) that lowers the proportional phosphate content in the mineral layer; the ratio of Hap-C is very close to $\mathrm{Ca} / \mathrm{P}$ ratio of octacalciumphosphate $(1,33)$, being likely $\mathrm{OCP}$ the main phase observed in HAp-C. Some substitution elements appear in Hap-A samples (Mg, Na to a lower extent) as usually seen when calcium phosphate is deposited from physiological solutions.

\section{Vibrational characterisation of layers}

The FTIR spectrum of the deposited layers is shown in Figure 3 in the $550-2000 \mathrm{~cm}^{-1}$ wavenumber interval. This is the most representative zone, since the $4000-2000 \mathrm{~cm}^{-1}$ zone only shows the large peak associated with hydrogen bonding and eventually water adsorbed on the samples and it does not differ significantly between the two samples. The choice of measuring the signal associated to the mineral layer only (by measuring the crushed coating after peeling it off from the substrate, instead of a reflectance 
measurement of the whole sample) gives good results and produces a reduction in the signal from the subjacent PCL. The peaks in the zone $1350-1550 \mathrm{~cm}^{-1}$ are associated with carbonate moieties (bending modes $v 3$ and $v 4$, stretching mode $v 3$ ). Peaks between $1000-1100 \mathrm{~cm}^{-1}$ are due to the triply degenerated asymmetric stretching mode of $\mathrm{P}-\mathrm{O}$ bond in phosphate group. Peaks between 550 and $650 \mathrm{~cm}-1$ are due to the triply degenerated bending mode of O-P-O bonds of the phosphate group. As can be easily seen in the spectrum, the signal associated with carbonate is higher in HAp-A relative to HAp-C, whereas the signal associated with phosphate groups is higher in HAp-C. Thus not only the carbonate content is higher in HAp-A but the phosphate content is lower, an indication that carbonate is substituting for $\mathrm{PO}_{4}{ }^{3-}$ in the lattice, as described for apatite deposited from SBF for carbonate concentrations lower than 20mM [25]. A further clue indicating that the B-substitution is predominant is the absence of a peak at $1550 \mathrm{~cm}^{-1}$ that appears when $\mathrm{CO}_{3}{ }^{2-}$ stands for $\mathrm{OH}$ (A-type substitution). OH typical signal is not observed at 630 and $3570 \mathrm{~cm}^{-1}$; this is frequently the case when analysing calcium phosphates deposited from SBF and also the case in apatite from bone that was not calcined [26]. Peak at $960 \mathrm{~cm}-1$ and shoulder at $1096 \mathrm{~cm}-1$ indicate $\mathrm{HPO}_{4}{ }^{2-}$ incorporation into the lattice. Both peaks are highly predominant in case of Hap-C, confirming that $\mathrm{OCP}$ (formula $\mathrm{Ca}_{8} \mathrm{H}_{2}\left(\mathrm{PO}_{4}\right)_{6}-5 \mathrm{H}_{2} \mathrm{O}$ ) is the main phase in presence. It can also be observed that in general the peaks from HAp-A are smoother and wider than the peaks of HAp-C, which is indicative of its amorphous nature (or very thin crystallite structure).

The spectrum obtained by X-ray diffraction is presented in Figure 4. The spectrum of pure PCL is shown below as a comparison, since PCL is semi-crystalline, and PCLassociated signal appears and must be differentiated from the signal associated with the mineral layer. PCL background spectrum mainly consists of two intense peaks at 
$2 \theta=21.6$ and $2 \theta=23.8$ (inset in Figure 4), that account for diffraction on the [110] and [200] planes respectively (PCL has a crystalline structure with polyethylene-like orthorhombic cell disposition, with lattice parameters $a=0.748 \mathrm{~nm}, b=0.498 \mathrm{~nm}$ and $\mathrm{c}=1.727 \mathrm{~nm}$ )[27]. Here again, the signal of HAp-C speaks for a more crystalline layer than that of HAp-A: the peaks are more defined, and their shape is more acute (in both cases the small size of the crystallites prevents from obtaining high peaks as usual when considering high-temperature sintered apatite). Most of the peaks observed are typical for hydroxyapatite, namely at 31,8; 32,2; 32,9 (respectively accounting for reflection on the planes of Miller indices [211], [112] and [300]); at 46,8; 48,3 and 49,7 (respectively accounting for reflections on [222], [312] and [213] planes). On the other hand, some other peaks observed match closely with another calcium phosphate phase, namely octacalciumphosphate (OCP): at 26,02 (plane [002], corresponding plane of HAp is at 25,8) and 53,32 (plane [004], corresponding plane of HAp is at 53.27). It is thus likely that both OCP and hydroxyapatite are present; it is generally considered in the literature that OCP and HAp are hard to distinguish due to closely related lattice parameters[28]: as a matter of fact c-dimension of HAp lattice is $0,688 \mathrm{~nm}$ whereas in OCP $\mathrm{c}=0,6855$ $\mathrm{nm}$. The peak that is generally used to differentiate both phases, and corresponds to reflection on [010] plane of OCP, at $2 \theta=4.72$, is out of the measure range in this case. Nevertheless other peaks may match the corresponding reflections in range from 25 to 50 degrees (see figure 4). As discussed later, in physiological solutions and biological environments HAp and OCP phases often coexist. The peaks of HAp-A cannot be precisely defined, due to generalized broadening related with the lattice distortion due to carbonate substitution but they correspond generally to those of HAp-C.

\section{Cell observation}


As can be seen on Figure 5 and 6, cells were able to adhere and spread on all supports tested. Actin cytosqueleton is more stretched on PCL and PCL-HAp-P surfaces, cells appear wider. On calcium phosphate surfaces, cell edges are sharper and irregular, and cell spreading is limited due to the roughness of the apatite surface, much higher than that of PCL bulk surface; as a result cell size is generally tinier. In terms of adhesion efficiency, PCL and PCL-HAp show low adhesion efficiency at $3 \mathrm{~h}$ in the culture conditions (11\% and $15 \%$ respectively when compared to initial seeding density) and cells were not evenly distributed on the samples. Calcium phosphate surfaces show a good cell adhesion, comparable to that of glass coverslip controls (Figure 7). There is a significative difference $(\mathrm{p}<0.05$, Student $\mathrm{t}$-test) between cell number observed on HApA and HAp-C, with more cells on HAp-C.

Discussion

\section{Deposition of calcium phosphate phase on biomaterials}

Deposition of apatite on materials when immersed in simulated body fluid has been described as a guarantee for their bioactivity in vivo. SBF is an aqueous solution that mimics the electrolyte content of blood plasma. The mechanism proposed for the deposition of a precursor phase of amorphous calcium phosphate that later evolves towards apatite involves the negative surface potential of materials[29], normally due to deprotonation of functional groups such as $-\mathrm{PO}_{4} \mathrm{H}_{2}$ [30],- $\mathrm{TiOH},-\mathrm{SiOH},-\mathrm{COOH}$ [31], -

$\mathrm{OH}$ at physiological $\mathrm{pH}(\sim 7,4)$ (this was demonstrated for hydroxyapatite [32], and the process is the same for many biomaterials). Negative surface potential has been related both with HAp deposition from SBF -whereas positive surface potential leads to preferential deposition of sodium chloride[29]- and good osteoblast behaviour. This negative surface potential attracts calcium ions and a calcium-rich calcium phosphate layer is formed. Then due to an excess of calcium ions the surface potential turns 
positive, and phosphate ions are now attracted in majority. This process is repeated and a layer is formed: this amorphous calcium phosphate layer, highly hydrated, is then remodelled to hydroxyapatite. Here, the plasma treatment performed is meant to generate carboxyl and hydroxyl moieties by scission of the esters of the PCL chain. As a matter of fact a strong decrease of the water contact angle of the PCL surface after plasma treatment (from $\sim 72$ to $\sim 34^{\circ}$, data not shown) show that polar groups have been generated on the surface. In previous experiments, the plasma treatment was seen to enhance the deposition rate of apatite, but to a lower amount than plasma treatment and nucleation. Nucleation by seeds of calcium phosphate was proposed first by Taguchi[33], and later by Oyane[17] as a mean to effectively accelerate apatite deposition: SBF is saturated towards apatite, and calcium phosphate seeds provide sites for heterogeneous nucleation, consequently the formation of solid phases is much easier. This is also the result we obtained in previous experiments where we also observed dramatically accelerated apatite formation rates on PCL scaffolds (reinforced or not with synthetic hydroxyapatite nanoparticles)[34] in traditional SBF after nucleation, as well as in previous experiments with this modification of SBF prepared with the Müller method; nevertheless it is important to mention that the decrease in sodium content associated with our modification of the Müller method seemed to cause a slower mineralisation than traditional SBF, which is likely to be due to the lower ionic strength of the solution. However, the lower sodium concentration did not impede the proper precipitation of the apatite layer, it being an adequate solution for performing the Kokubo-test (if not comparing the results obtained with the results obtained with traditional SBF) or for covering the materials with a mineral layer. From a practical point of view, the method from Müller has unbeatable advantages such as simplicity, easiness of use and reproducibility. Matching the traditional SBF concentrations but 
using the methodology of the stock solutions is also possible (also mentioned by Lemaitre et al. in its useful critic of Kokubo test [35]).

\section{Nature of the mineral layer}

It is known from the literature that the composition, concentration [36] and $\mathrm{pH}$ of SBF greatly influences the nature of the apatite layer deposited. A more basic $\mathrm{pH}$, due to $\mathrm{OH}$ being one of the components of hydroxyapatite, favours the precipitation of apatite raising the supersaturation in the solution[19]. Concentrated SBF, such as 1,5xSBF, $2 \mathrm{xSBF}$, has been shown to result in a more crystalline, less carbonated structure[37]. Müller et al. have shown that carbonate content in SBF not only influences the carbonate content in the deposited layer[18], but also the preferred orientation growth of the crystals as well as the main crystallite dimension[25]. As a matter of fact, carbonate as well as magnesium has been shown to act as crystal growth inhibitor, in the case of the carbonate this may be due to the inactivation of crystal growth sites by the adsorption of these divalent cations in place of $\mathrm{Ca}^{2+}[38]$. In this work, the influence of these ions was predominant for tuning the crystallinity and crystal size, as observed by electron microscopy, FTIR and XRD. The crystal size and crystallinity of the mineral deposited has a significant influence on biosolubility [39], as well as on the topography and likely protein adsorption on the surface and has thus a decisive influence on the cell behaviour [40].

From FTIR and XRD results the deposited phase in HAp-A appears to be a carbonated hydroxyapatite with low crystallinity due to carbonate content and high carbonate substitution. FTIR results lead us to believe that the deposited apatite is B-Substituted with carbonate standing for phosphate. This is more likely when phosphate appears as hydrogen phosphate due to the equality of charges carried by both cations. As a result of the equilibrium between phosphate and hydrogen phosphate at physiological $\mathrm{pH}$, a part 
of the phosphates is often replaced by hydrogen phosphates, broadening the triply degenerated band for asymmetric stretching mode of P-O at $1000-1100 \mathrm{~cm}^{-1}$ and lowering the $\mathrm{Ca} / \mathrm{P}$ value $[20,41]$. In the case of HAp $\mathrm{C}$, the strong signal associated with hydrogenphosphate and higher peak definition and crystallinity leads to think that hydrogenphosphate may not be present as a substitution but as a stoechiometric component of octacalciumphosphate, an acidic calcium phosphate, which has been described as an apatite precursor in vitro[42,43]. Although XRD data is not totally conclusive (only peak at 4,72 is only seen for $\mathrm{OCP}$ ), the $\mathrm{Ca} / \mathrm{P}$ ratio observed, abundance of hydrogenophosphates and crystal morphology observed speak for OCP being the main phase deposited. In physiological solution, although apatite is the thermodynamically most stable phase, OCP is often formed due to faster kinetics of deposition [44]. Later transformation to HAp is driven by the metastable character of OCP, and is favoured by the very low interfacial tension between both components[45]. The mechanism proposed for OCP hydrolysis to HAp is a topoaxial conversion by ion diffusion within the crystal lattice, which would explain the conservation of macroscopic crystal structure upon formation of HAp from OCP [25, 46]. This hydrolysis process has been described both in vitro [24] and in vivo [47] with synthetic OCP; some researchers relate the osteoconductive potential of OCP to its transient character, considering its conversion to HAp a key factor for bone regeneration, osteoblast and osteoclast activation [46]. Nevertheless it is not clear that OCP appears as an endogen apatite precursor during the mineralization of human tissues [48]. Here the clues that point towards presence of both OCP and HAp phases, could be explained by the formation of OCP and partial hydrolysis of OCP phase to HAp: it would explain the low $\mathrm{Ca} / \mathrm{P}$ ratio observed $(1,35)$ for $\mathrm{HAp}-\mathrm{C}$ : partially hydrolyzed OCP samples from Suzuki et al. had similar ratios ranging from 1,33 to 1,49 [46,47]. Although OCP has a 
stoechiometric $\mathrm{Ca} / \mathrm{P}$ ratio of 1,33 in the aforementioned papers synthetic OCP had a ratio before hydrolysis of 1,26 and this ratio raised upon hydrolysis. High intensity ratios of the peaks [002] and [004] seen in the diffractogramm lead to think that crystal growth along c-axis is favoured.

\section{Cell behaviour}

Apatite morphology is decisive for cell behaviour, and whereas synthetic hydroxyapatite and calcium phosphates have been studied from the biological point of view, there is still a lack of information about cell response to different biomimetic apatites; the available studies show that behaviour is altered by very slight changes in morphology and chemistry and a thin analysis of the layer formed is thus of uttermost importance. Hydroxyapatite as a bulk sintered material has been shown be osteoinductive in vivo $[49,50,51]$ and to induce stem cell differentiation towards the osteogenic pathway in vitro, and the response of osteoblasts to different mimetic apatites has also been described. A toxic effect of very amorphous calcium phosphate has been described [52] likely due to dissolution of both calcium and phosphate that causes apoptosis [53], but there is no much data on the effect of different types of hydroxyapatite on bony cells. Our first and preliminary results about osteoblast-like cells behaviour on the engineered apatite layers with different topographies, chemistry and crystallinity show that both types of surfaces support cell adhesion and short term viability of osteoblast-like stem cells. In this first set of experiments, morphologic differences have been seen between cells adhered on PCL or PCL-HAp-P surfaces on one side, and HAp layers on the other. A low adhesion on PCL surfaces was seen, maybe due to poor protein adsorption (very smooth surface) or due to cytotoxic effect of plasma treatment; this should be further explored since in previous experiments without plasma treatments PCL and PCL-HAp P supports elicited cell adhesion and 
proliferation. Morphology on calcium phosphate surfaces was very different; cells were not wide spread, appeared tinier and grained actin was observed inside of the cells. This was also described in the work of Okada [40]. Recent cell research shows that cell morphology and cell cytosqueleton organization in consequence of cell-material interaction and focal adhesion organization is closely related to cell fate[54], including phenotypic expression, intracellular metabolic and catabolic pathways signalization, migration behaviour and so on[55]. Significant difference in cell density at $3 \mathrm{~h}$ after seeding was observed between both calcium phosphates, so at longer times behaviour should arise many more significant differences. ${ }^{1} \mathrm{We}$ are looking forward to further characterize these coatings from the biological point of view in order to gain fundamental knowledge about cell-material interaction, which will help us design better composite biomaterials for efficient bone tissue engineering; in particular, study of protein conformation on substrate with different morphology and crystal chemistry should gain in understanding cell behaviour. Although this type of coating may not be used in load bearing applications due to its tendency to crack and peel off, it could be used for the entrapment of drugs and proteins or as a laboratory tool for studying cellmaterial interactions.

\section{Conclusions}

An apatite-like mineral layer can be deposited on the surface of polycaprolactone substrates by immersing them in simulated body fluids. SBF preparation from stock solutions proved to be more efficient, user-friendly and repetitive than direct preparation from salt weighing. Previous activation of the PCL surface by plasma treatment followed by nucleation by alternative immersion in $\mathrm{CaCl}_{2}$ and $\mathrm{K}_{2} \mathrm{HPO}_{4}$ solutions proved itself to be very effective in accelerating apatite deposition. The composition and 
morphology of the apatite layer produced can be easily tailored by modifying the concentration of the different ions in SBF medium; the immersion of nucleated PCL sheets in a carbonate rich SBF medium produces a layer of low-crystallinity apatite with the classical cauliflower morphology. The absence of magnesium and carbonate ions increases crystallinity, and thickness of the apatite layer changing the crystal morphology and decreasing the $\mathrm{Ca} / \mathrm{P}$ ratio to values of 1.35 ; it is likely octacalcium that has been partially hydrolyzed to HAp. Preliminary cell culture results show that cells can adhere to the HAp-coated materials independently of their composition; nevertheless the cells show different morphologies on the different supports and adhesion is influenced by topography and chemistry, being adhesion most efficient on HAp-C; effects related with these changes in morphology and further influence will give clues on how to produce the best environment for bone tissue engineering.

\section{Acknowledgements}

Support of the Spanish Ministry of Science through project No. MAT2007-66759-C0301, including the FEDER financial support, with complementary funding of Generalitat Valenciana with project ACOMP/2009/112 and Universidad Politécnica de Valencia with 2911-2008 project is acknowledged. JLGR and JSA acknowledge funding from the Centro de Investigación Principe Felipe in the field of Regenerative Medicine through the collaboration agreement of the Conselleria de Sanidad (Generalitat Valenciana), and the Instituto de Salud Carlos III (Ministry of Science and Innovation). Myriam Lebourg thanks Patricia Rico and Cristina Martinez for help and advice with culture experiments and CIBER-BBN for funding. CIBER-BBN is an initiative funded by the VI National R\&D\&i Plan 2008-2011, Iniciativa Ingenio 2010, Consolider Program, CIBER Actions and financed by the Instituto de Salud Carlos III with assistance from the European Regional Development Fund. 


\section{Figure Captions}

Table 1. Electrolyte concentration of simulated body fluids employed

Figure 1. Morphology of the deposited calcium phosphate layers

Figure 2. Profile of the layers: A-HAp, left (bar size 10 $\mu \mathrm{m}$ ) and C-HAp, right (bar size 30 $\mu \mathrm{m})$

Figure 3. FTIR spectrum of deposited layers: amorphous apatite (A-HAp) and crystalline apatite (C-HAp) in the range 550-2000 $\mathrm{cm}^{1}$. Peaks marked with stars are due to PCL residue.

Figure 4. X-ray Diffraction spectrum of PCL and HAp covered PCL samples with corresponding Miller indices of HAp (black) and OCP (gray)

Figure 5. MT3C3 cells adhered on PCL, PCL with HAp nanoparticles (PCL HAp P), and calcium phosphate surfaces (bar size up $30 \mu \mathrm{m}$, bottom 60 $\mu \mathrm{m}$ )

Figure 6. Cell morphology on the different supports as observed by fluorescence microscopy (green actin filaments-blue nuclei, bar size $50 \mu \mathrm{m}$ )

Figure 7. Cell density on the different surfaces as determined by image analysis

1. Wang M. Developing bioactive composite materials for tissue replacement. Biomaterials 2003;24: 2133-2151.

2. Van Landuyt P, Li F, Keustremans JP, Delannay F, Munting E. Influence of high sintering temperature on the mechanical properties of Hydroxyapatite. J. Mater. Sci. Mater. Med. 1995; 6: 8-13.

3. Hasegawa S, Neo M. Tamura J, Fujibayashi S, Takemoto M, Shikinami Y, Okazaki K, Nakamura T. In vivo evaluation of a porous hydroxyapatite/polyDL-lactide composite for bone tissue engineering. J Biomed Mat Res 2007; 81A: 930-938.

4. Shor L, Güçeri S, Wen X, Gandhi M, Sun W. Fabrication of three-dimensional polycaprolactone/ hydroxyapatite tissue scaffolds and osteoblast scaffold interactions in vitro Biomaterials 2007; 28:52915297.

5. Kenny SM, Buggy M. Bone cements and fillers: a review J of Mat Sci Mat Med 2003; 14: 923-938

6. Azevedo HS, Leonor IB, Alves CM, Reis RL. Incorporation of proteins and enzymes at different stages of the preparation of calcium phosphate coatings on a degradable substrate by a biomimetic methodology. Materials Science and Engineering 2005;C 25:169-179

7. Chen Y, Mak AFT, Wang M, Li J, Wong MS. PLLA scaffolds with biomimetic apatite coating and biomimetic apatite/collagen coating to enhance osteoblast-like cells attachment and activity. Surf Coat Tech 2006; 201(3): 575-580.

8. Ciapetti G, Ambrosio L, Savarino L, Granchi D, Cenni E, Baldini N, Pagani S, Guizzardi S, Causa F, Giunti A. Osteoblast growth and function in porous poly( $\varepsilon$-caprolactone) matrices for bone repair: a preliminary study. Biomaterials 2003; $24: 3815-3824$.

9. Murphy WL, Hsiong S, Richardson TP, Simmons CA, Mooney DJ. Effect of a bone-like mineral film on phenotype of adult human mesenchymal stem cells in vitro. Biomaterials 2006; 26: 303-310.

10. Chim H, Hutmacher DW, Chou AM, Oliveira AL, Reis RL, Lim TC, Schantz JT. A comparative analysis of scaffold material modifications for load bearing applications in bone tissue engineering. Int $\mathrm{J}$ Oral Maxillofac Surg. 2006; 35(10):928-34.

11. Lickorish D, Ramshaw JAM, Werkmeister JA, Glattauer V, Howlett CR. Collagen hydroxyapatite composite prepared by biomimetic process. J Biomed Mat Res 2004; 68A: 19-27.

12. Kim HW, Kim HE, Salih V. Stimulation of osteoblast responses to biomimetic nanocomposites of gelatin-hydroxyapatite for tissue engineering scaffolds. Biomaterials 2005; 26: 5221-5230.

13. Kim SS, Park MS, Gwak SJ, Choi CY, Kim BS. Accelerated bonelike apatite growth on porous Polymer/ceramic composite scaffolds in vitro. Tissue Engineering 2006; 12(10): 2997-3006. 14. Chou L, Marek B, Wagner WR. Effect of Hydroxylapatite coating crystallinity on biosolubility, cell attachment efficiency and proliferation in vitro. Biomaterials 1999; 20(10): 977-985.

15. Nagano M, Nakamura T, Kokubo T, Tanahashi M, Ogawa M. Differences of bone bonding ability and degradation behaviour in vivo between amorphous calcium phosphate and highly crystalline hydroxyapatite coating. Biomaterials 1996; 17(18):1771-1777.

16. Chou YF, Huang W, JCY Dunn, Miller TA, Wu BM. The effect of biomimetic apatite structure on osteoblast viability, proliferation, and gene expresión. Biomaterials 2005; 26(3) 285-295.

17. Oyane A, Uchida Y, Choong C, Triffitt J, Ito A. Simple surface modification of poly(e-caprolactone) to induce its apatite-forming ability. J Biomed Mat Res A 2005; 75(1):138-145. 
18. Müller L, Müller FA. Preparation of SBF with different $\mathrm{HCO}_{3}{ }^{-}$content and its influence on the composition of biomimetic apatites. Acta Biomaterialia 2006; 2(2): 181-189.

19. Planell JA, Gil FJ, Padrós A, Manero JM, Aparicio C, Nilsso M. Growth of bioactive surfaces on titanium and its alloys for orthoepaedic and dental implants. Mat Sci \& Eng C 2002; 22(1): 53-60. 20 . Koutsopoulos S. Synthesis and characterization of hydroxyapatite crystals: a review study on the analytical methods. J Biomed. Mater. Res 2002; 62:600-612.

21. Selinummi J, Seppälä J, Yli-Harja O, Puhakka JA. Software for quantification of labeled bacteria from digital microscope images by automated image analysis. BioTechniques 2005; 39(6): 859-863. 22. Vallés Lluch A, Gallego Ferrer G, Monleón Pradas M. Biomimetic apatite coating on P(EMA-coHEA)/SiO2 hybrid nanocomposites. Polymer 2009; 50(13):2874-2884.

23. Mandel S, Tas AC. Brushite (CaHPO4.2H2O) to octacalcium phosphate (Ca8(HPO4)2(PO4)4.5H2O) transformation in DMEM solutions at $36.5^{\circ} \mathrm{C}$. Materials Science and Engineering C 30 (2010) 245-254 24. Horváthová R, Müller L, Helebrant A, Greil P, Müller FA. In vitro transformation of OCP into carbonated HA under physiological conditions. Materials Science and Engineering C 28 (2008) 14141419

25. Müller L, Conforto E, Caillard D, Müller FA. Biomimetic apatite coatings-carbonate substitution and preferred growth orientation. Biomol Eng 2007; 24: 462-466.

26. Pasteris JD, Wopenka B, Freeman JJ, Rogers K, Valsami-Jones E,vane der Houwen JAM, Silva MJ. Lack of $\mathrm{OH}$ in nanocrystalline apatite as a function of degree of atomic order: implications for bone and materials. Biomaterials 2004; 25:229-238.

27. Bittiger H, Marchessault RH, Niegisch WD. Crystal structure of polycaprolactone. 1970 Acta Cryst. B 1970; 26:1923-1927.

28. Lu X, Leng Y. TEM study of calcium phosphate precipitation on bioactive titanium surfaces. Biomaterials 2004; 25: 1779-1786

29. Bodhak S, Bose S, Bandyopadhyay A. Role of surface charge and wettability on early stage mineralization and bone cell-materials interactions on polarized Hydroxyapatite. Acta Biomaterialia 2009; 5(6): 2178-2188.

30. Oliveira AL, Mano JF, Reis RL. Nature-inspired calcium phosphate coatings: present status and novel advances in the science of mimicry. Curr Opin Sol State Mat Sci 2003; 7: 309-318.

31. Kawashita M, Nakao M, Minoda M, Kim HM, Beppu T, Miyamoto T, Kokubo T, Nakamura T. Apatite forming ability of carboxyl containing polymer gels in a simulated body fluid. Biomaterials 2003; 24(14):2477-2484.

32. Kim HM, Himeno T, Kokubo T, Nakamura T. Process and kinetics of bonelike apatite formation on sintered hydroxyapatite in a SBF. Biomaterials 2005; 26(21): 4366-4373.

33. Taguchi T, Muraoka Y, Matsuyama H, Kishida A, Akashi M. Apatite coating on hydrophilic polymer-grafted poly(ethylene) films using an alternate soaking process. Biomaterials 2001; 22(1): 53-58. 34. Lebourg M, Antón JS, Ribelles JL. Hybrid structure in PCL-HAp scaffold resulting from biomimetic apatite growth. J Mater Sci Mater Med. 2009, In press

35. Bohner M, Lemaitre J. Can bioactivity be tested in vitro with SBF solution? Biomaterials 2009; 30(12): 2175-2179.

36. Kim HM, Kishimoto K, Miyaji F, Kokubo T, Yao T, Suetsugu Y, Tanaka J, Nakamura T. Composition and structure of the apatite formed on PET substrates in SBF modified with various ionic activity products. J Biomed Mater Res 1999; 46: 228-235.

37. Stoch A.; Jastrzebski W.; Brozek A.; Stoch J.; Szaraniec J.; Trybalska B.; Kmita G. FTIR absorptionreflection study of biomimetic growth of phosphates on titanium implants. J. of Mol Struct 2000; 555(1) 375-382.

38. Johnsson MSA, Nancollas GH. The role of brushite and octacalcium phosphate in apatite formation. Critical Reviews in Oral Biology and Medicine 1992; 3 (1/2): 61-82.

39. Rey C, Combes C, Drouet C, Sfihi H, Barroug A. Physico-chemical properties of nanocrystalline apatites: Implications for biominerals and biomaterials. Materials Science and Engineering C 2007; 27: 198-205.

40. Okada S, Ito H, Nagai A, Komotori J, Imai H. Adhesion of osteoblast-like cells on nanostructured Hydroxyapatite. Acta Biomaterialia, In press

41. Landi E, Tampieri A, Celotti G, Langenati R, Sandri M, Sprio S. Nucleation of biomimetic apatite in synthetic body fluids: dense and porous scaffold development. Biomaterials 2005; 26(16): 2835-2845. 42. Dorozhkin S.Calcium Orthophosphates in Nature, Biology and Medicine. Materials 2009; 2:399-498 43. Lu X, Leng Y, Biomaterials 2005; 26: 1097 
44 . Horváthová R, Müller L, Helebrant A, Peter Greil P, Müller FA. In vitro transformation of OCP into carbonated HA under physiological conditions. Materials Science and Engineering 2008; C 28: 14141419

45. Liu Y, Wu W, Sethuraman G, Nancollas GH. Intergrowth of calcium phosphates: an interfacial energy approach. Journal of Crystal Growth 1997;174: 386-392

46. Suzuki O. Review: Octacalcium phosphate: Osteoconductivity and cristal chemistry. Acta

Biomaterialia, in press

47. Suzuki O, Kamakura S, Katagiri T Review: Surface Chemistry and Biological Responses to Synthetic Octacalcium Phosphate.

48. Grynpas MD. Transient precursor strategy or very small biological apatite crystals? Bone 2007; 41: 162-164.

49. Klein CPAT, de Groot K, Chen W, Li Y, Zhang X. Osseous substance formation induced in porous calcium phosphate ceramics in soft tissues. Biomaterials 1994; 15: 31-34.

50. Yamasaki H, Saki H. Osteogenic response to porous Hydroxyapatite ceramics under the skin of dogs. Biomaterials 1992; 13:308-312.

51. Ripamonti U. Osteoinduction in porous hydroxyapatite implanted in heterotopic sites of different animal models. Biomaterials 1996; 17: 31-35

52. Oreffo ROC, Triffitt JT. In vitro and in vivo methods to determine the interactions of osteogenic cells with biomaterials. Journal of Mat Sci Mat Med 1999; 10: 607-611

53. Adams CS, Mansfield K, Perlot RL, Shapiro IM. Matrix Regulation of Skeletal Cell Apoptosis: Role of calcium and phosphate ions. J Biological Chemistry 2001; 276 (23) 20316-20322

54. DeMali KA, Krister Wennerberg K, Keith Burridge K. Integrin signaling to the actin cytoskeleton Current Opinion in Cell Biology 2003, 15:572-582

55. Lock JG, Wehrle-Haller B, Strömblad S. Cell-matrix adhesion complexes: Master control machinery of cell migration. Seminars in Cancer Biology 2008; 18: 65-76 
ACCEPTED MANUSCRIPT
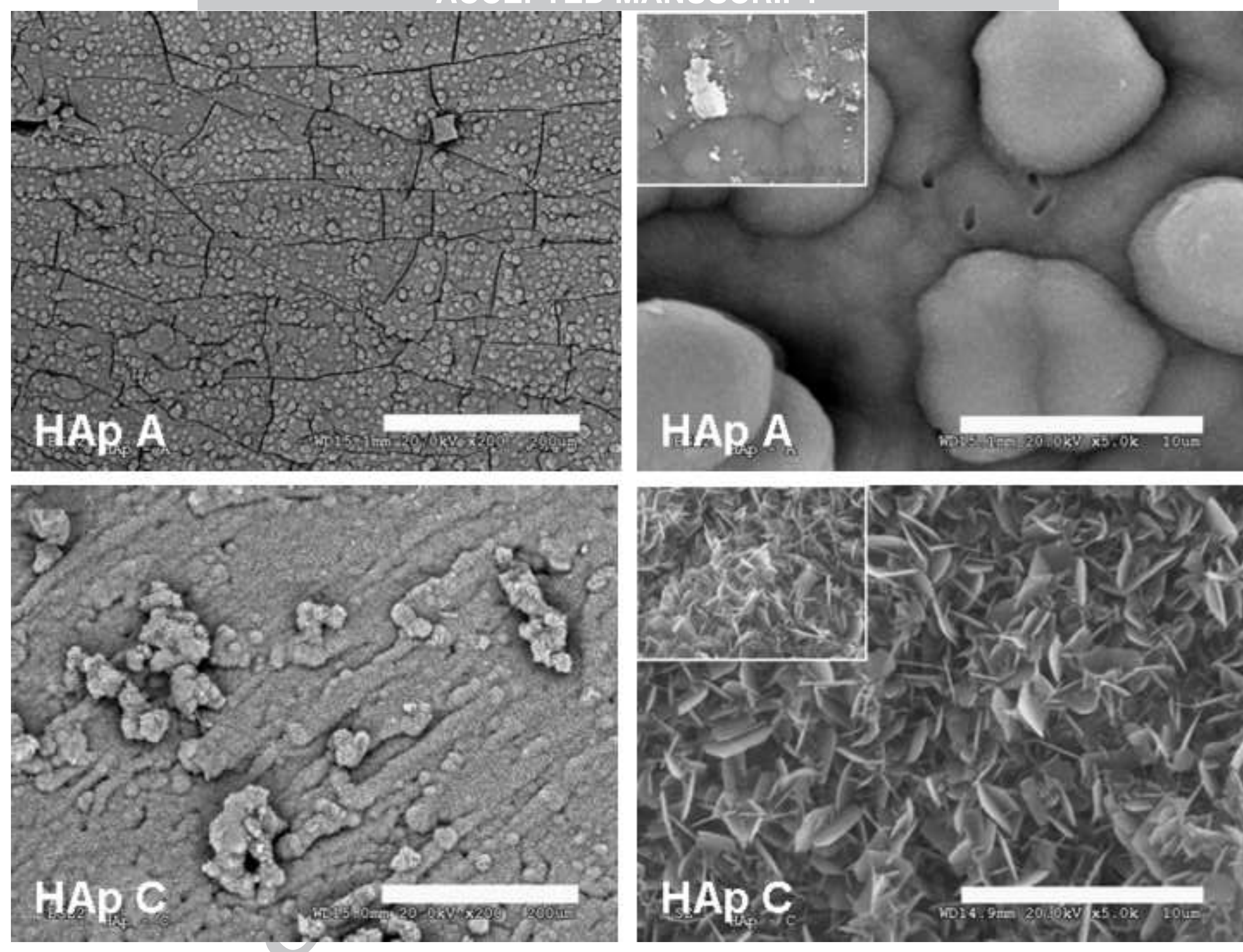
$\nabla$ 

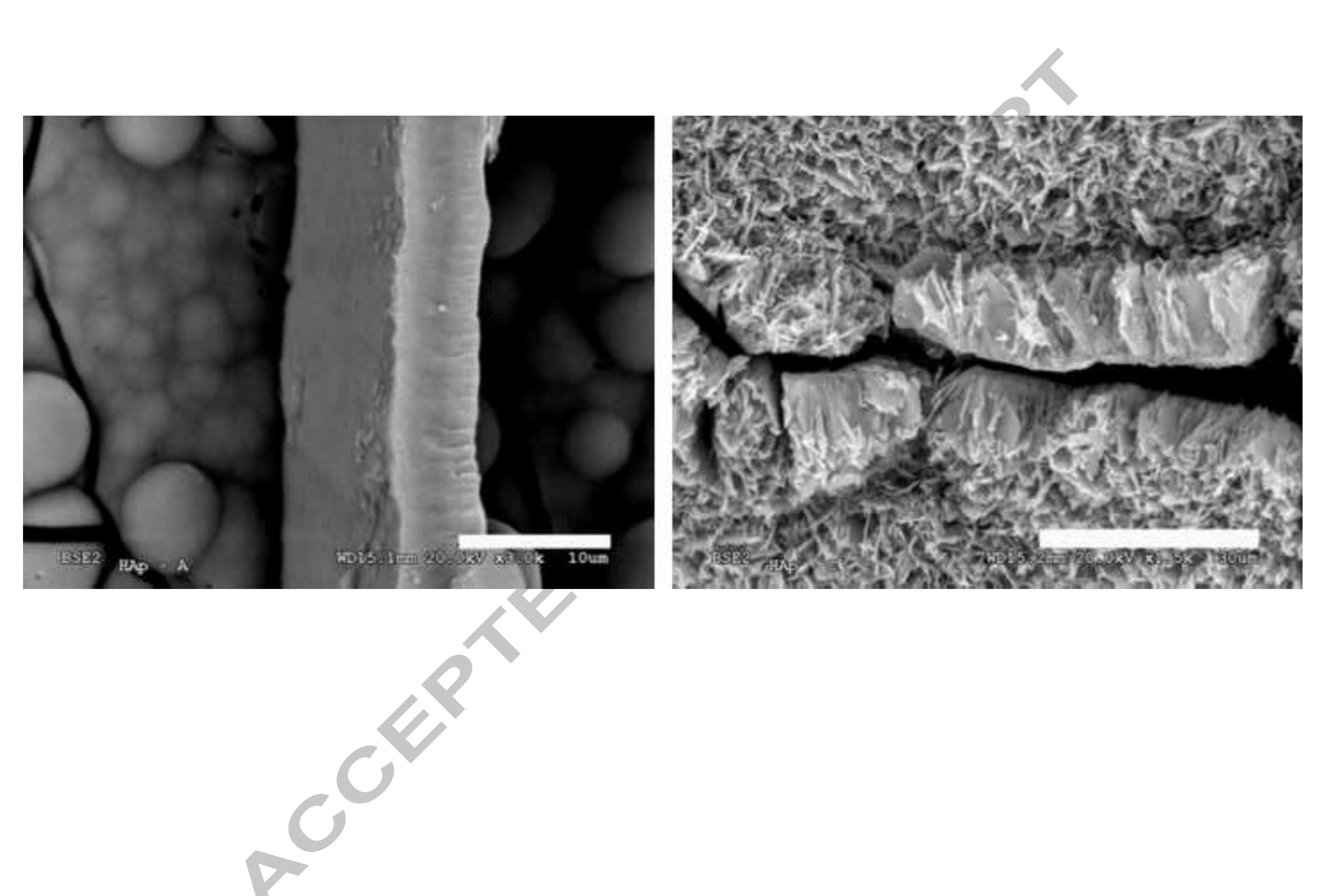

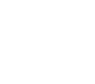

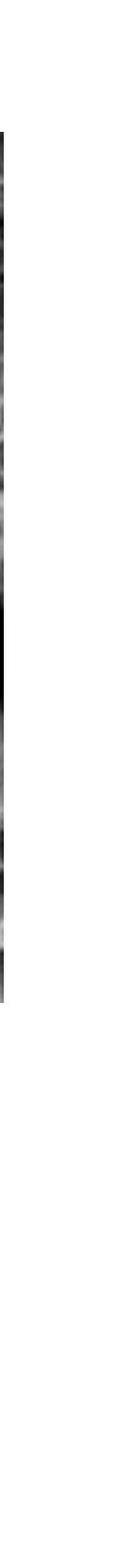




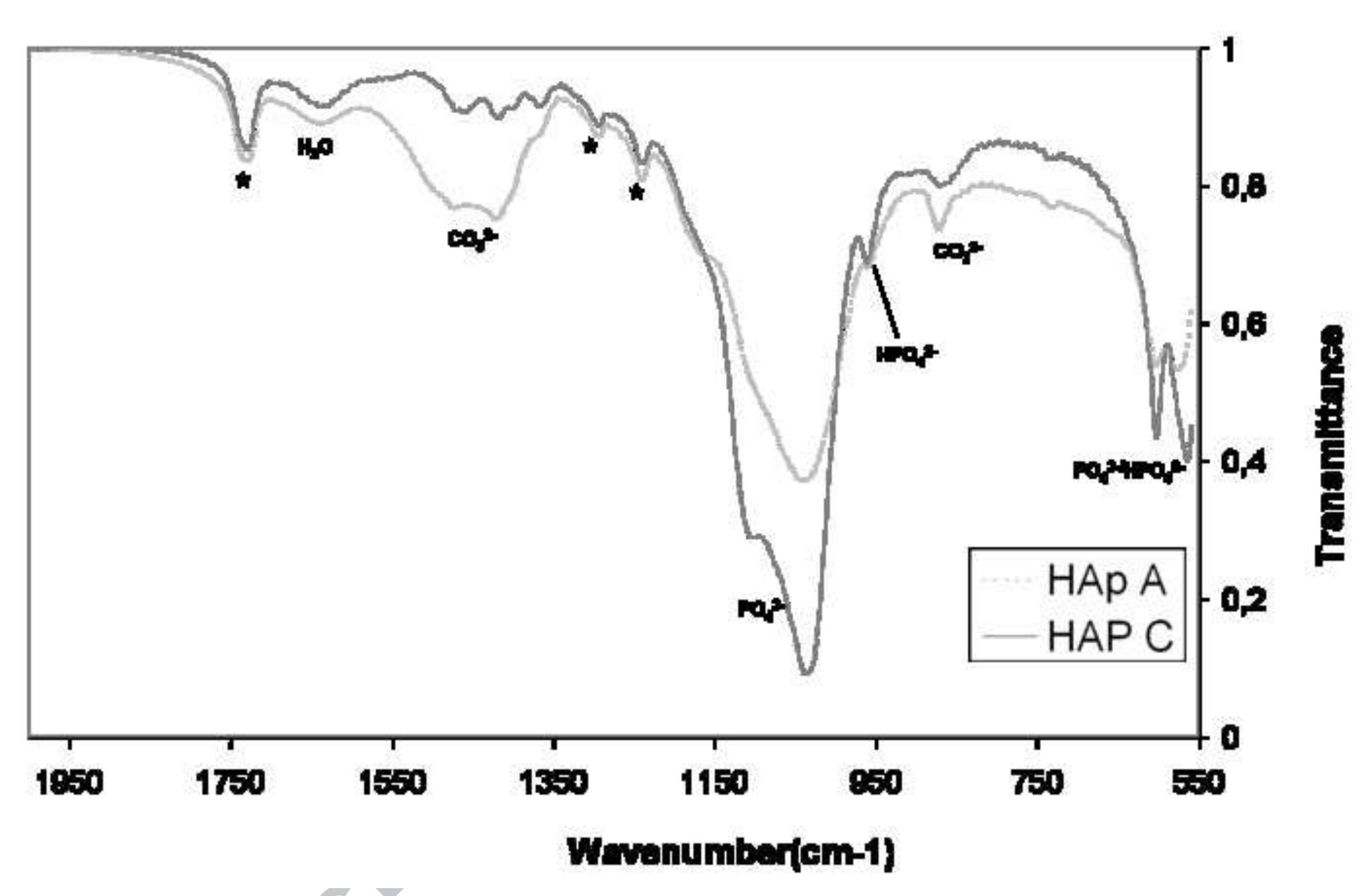

\section{Wrvonumber(cm-1)}

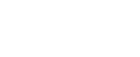

ACCEPTED MANUSCRIPT

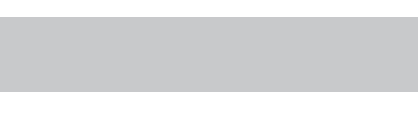




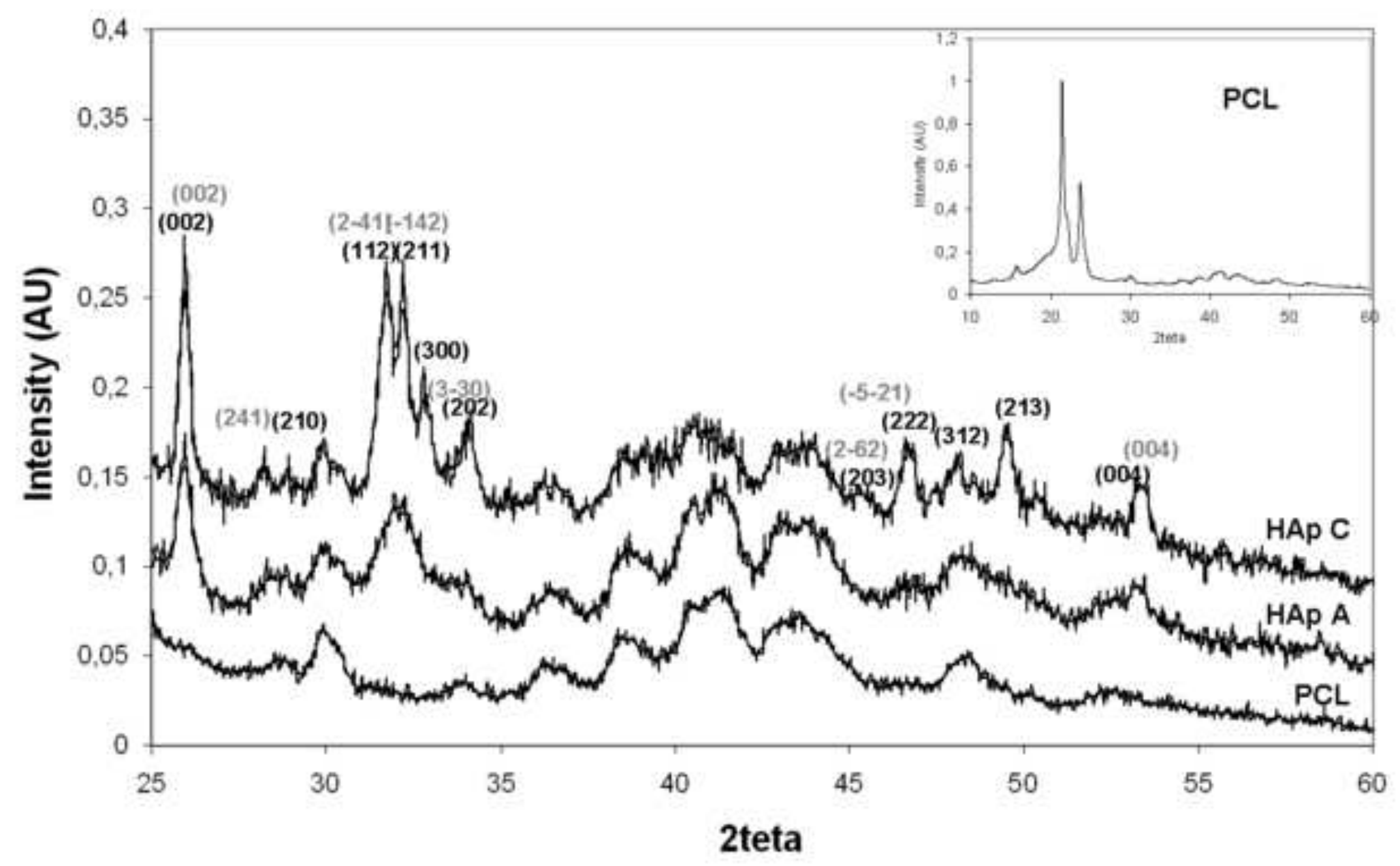




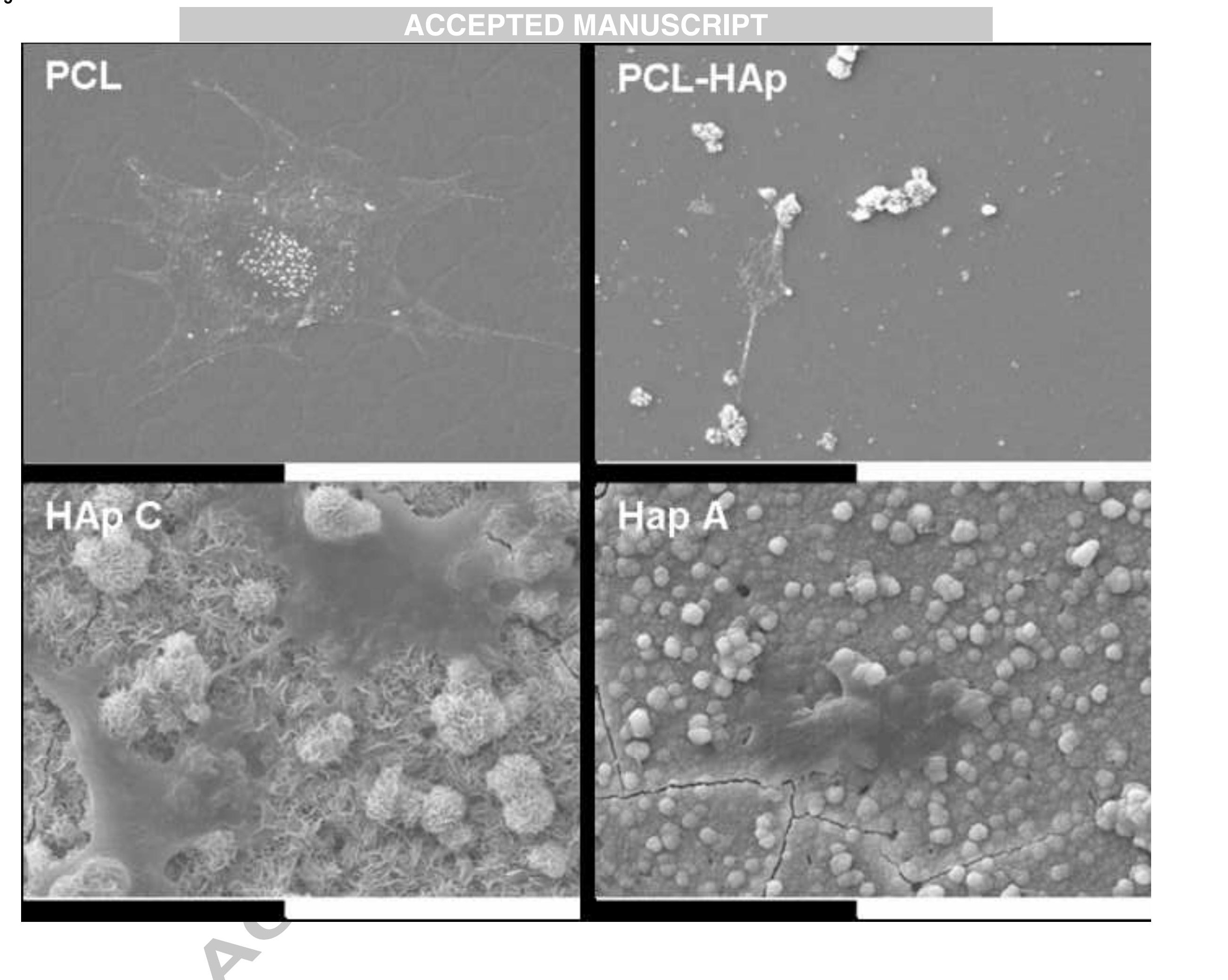
$\nabla$ 


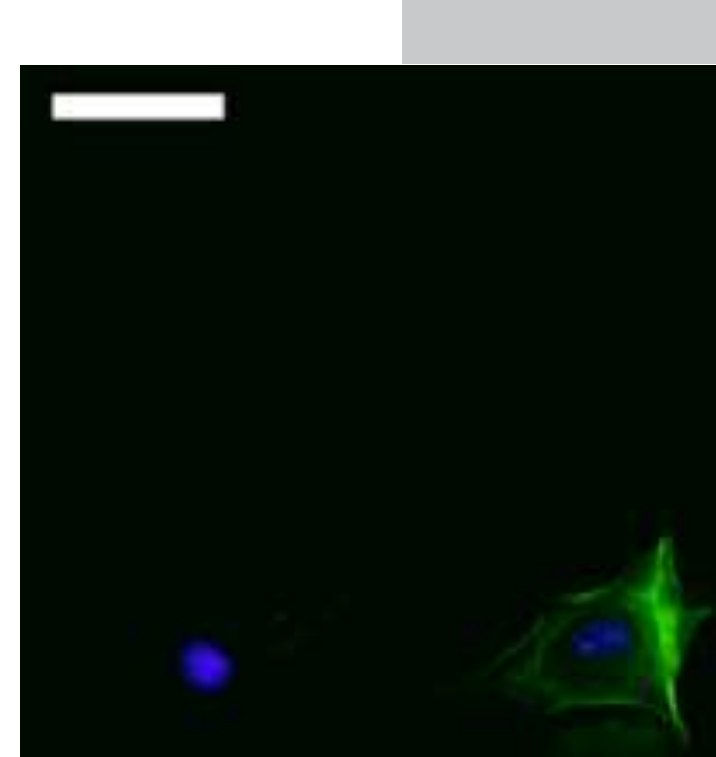

PCL

PCL- HAp P

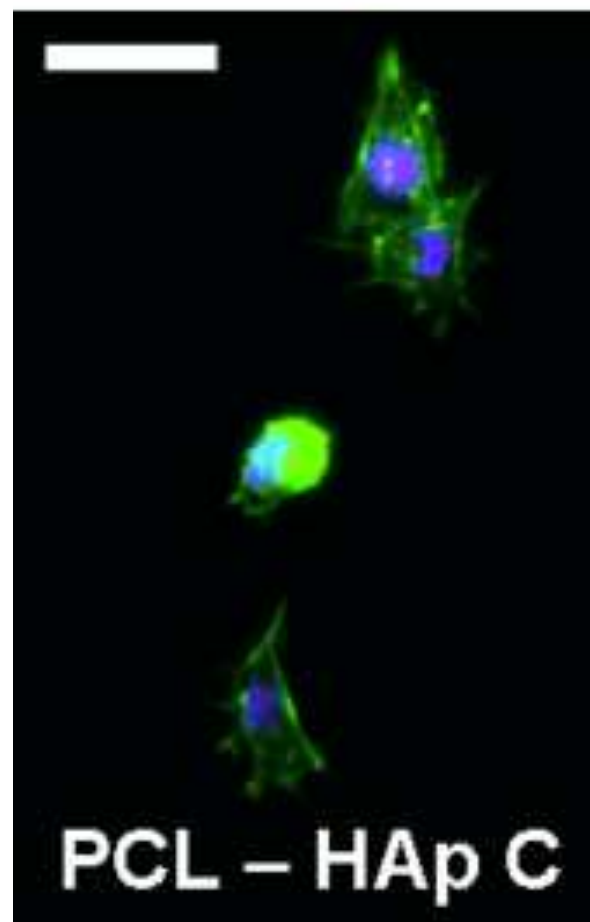

aㅡ

-

6)

PCL - HAp A 


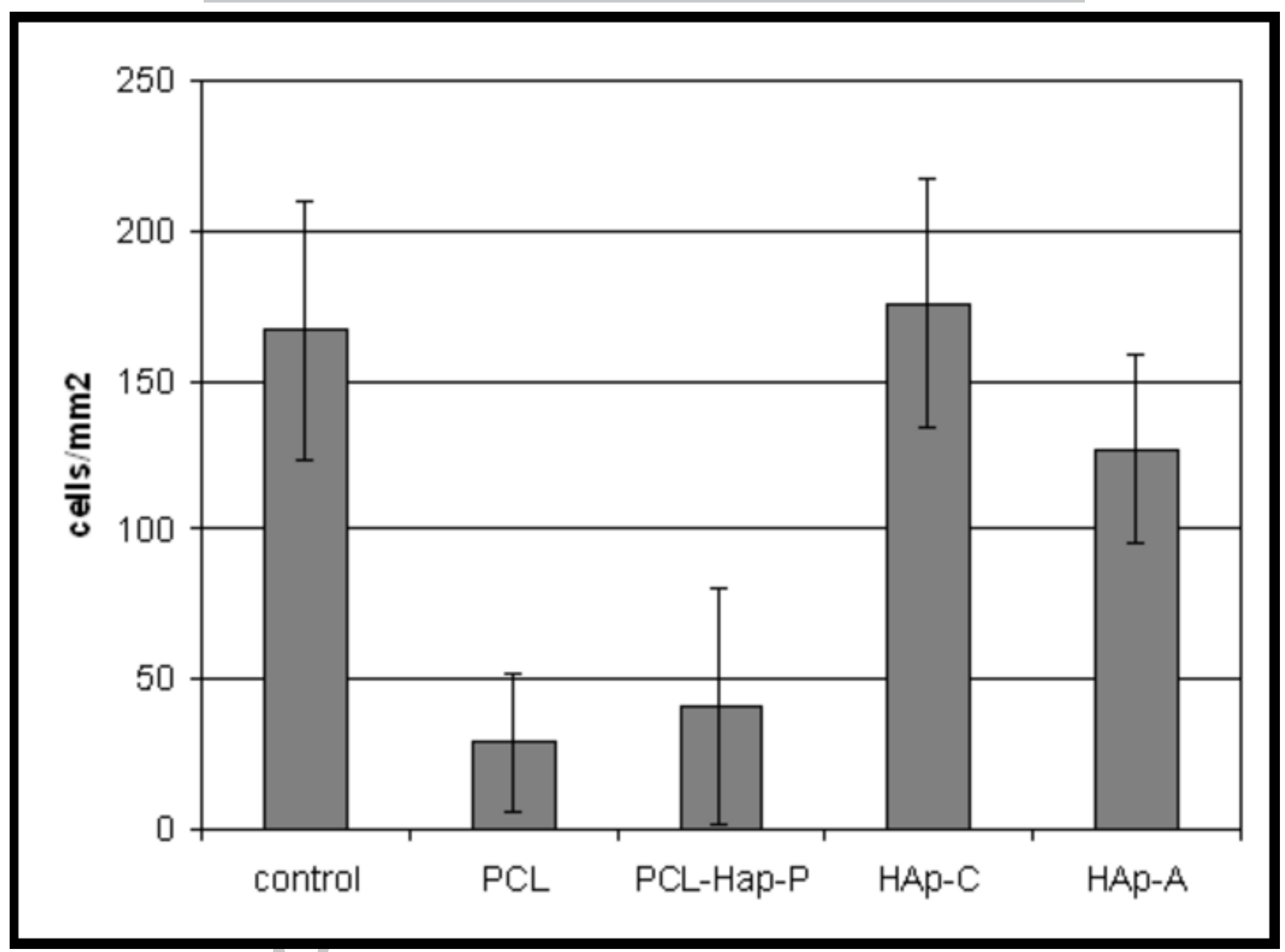

ACCEPTED MANUSCRIPT

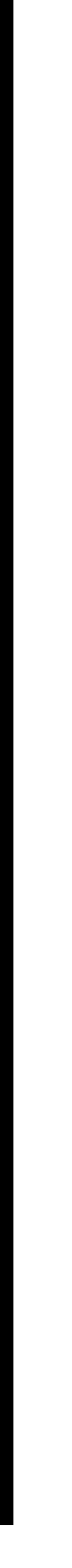




\begin{tabular}{|l|c|c|}
\hline $\begin{array}{l}\text { Electrolyte } \\
\text { concentration }\end{array}$ & $\begin{array}{c}\text { SBF-A } \\
(\mathrm{mM} /)\end{array}$ & $\begin{array}{c}\text { SBF-C } \\
(\mathrm{mM} /)\end{array}$ \\
\hline $\mathrm{Na}$ & 130,0 & 287,5 \\
\hline $\mathrm{K}$ & 3,7 & 7,4 \\
\hline $\mathrm{Ca}$ & 2,5 & 5,0 \\
\hline $\mathrm{Mg}$ & 1,0 & 0,0 \\
\hline $\mathrm{Cl}$ & 122,7 & 302,8 \\
\hline $\mathrm{HCO}$ & 15,0 & 0,0 \\
\hline $\mathrm{SO}_{4}$ & 1,0 & 0,0 \\
\hline $\mathrm{HPO}_{4}$ & 1,0 & 2,0 \\
\hline
\end{tabular}

